Tropical Journal of Pharmaceutical Research October 2013; 12 (5): 767-770

ISSN: $1596-5996$ (print); 1596-9827 (electronic)

(C) Pharmacotherapy Group, Faculty of Pharmacy, University of Benin, Benin City, 300001 Nigeria.

All rights reserved.

Available online at http://www.tjpr.org

Original Research Article

http://dx.doi.org/10.4314/tjpr.v12i5.16

\title{
Comparative Clinical Study on the Effectiveness of Homeopathic Combination Remedy with Standard Maintenance Therapy for Dengue Fever
}

\author{
Syed Saeed-ul-Hassan ${ }^{1}$, Imran Tariq ${ }^{1^{*}}$, Ayesha Khalid ${ }^{2}$ and Sabiha Karim ${ }^{1}$ \\ ${ }^{1}$ University College of Pharmacy, University of the Punjab, ${ }^{2}$ Department of Pharmacy, The University of Lahore, Lahore, \\ Pakistan -54000 .
}

*For correspondence: Email: imran_1982@hotmail.com; Tel: 0092-322-4218583, 0092-42-36156006

Received: 13 August 2012

Revised accepted: 28 June 2013

\begin{abstract}
Purpose: To investigate the effectiveness of homeopathic combination remedy compared with standard maintenance therapy for the treatment of dengue fever.

Method: A total of 50 patients with dengue fever were divided into two equal groups. Group 1 was treated with homeopathic combination remedy for consecutive 6 days while standard maintenance therapy was similarly given to Group 2 patients. Their full blood count (FBC) including platelet count $(P L T)$, white blood cell count (WBC) and hematocrit level (HCT) were recorded The parameters were monitored daily in order to determine between the two groups.

Results: Following the six-day homeopathic combination remedy, PLT count increased from (95.60 \pm $0.04) \times 10^{3}$ to $(311 \pm 0.13) \times 10^{3} / \mu \mathrm{L}$, and WBC from $(79.5 \pm 0.05) \times 10^{4}$ to $(90.3 \pm 0.02) \times 10^{4} / \mu \mathrm{L}$. However, HCT decreased from $48.02 \pm 6.70$ to $42.32 \pm 3.42 \%$. On the other hand, standard maintenance therapy increased PLT count from $(73.44 \pm 0.04) \times 10^{3}$ to $(239.00 \pm 0.04) \times 10^{3} / \mu \mathrm{L}$ and WBC from $(53.50 \pm 0.02) \times 10^{4}$ to $(79.40 \pm 0.02) \times 10^{4} / \mu \mathrm{L}$, but decreased HCT from $42.30 \pm 2.48$ to $39.68 \pm 4.35 \%$. A significant difference was seen in the PLT count, WBC and HCT level between the two therapies ( $p=0.012,0.003$ and 0.021, respectively).

Conclusion: The homeopathic combination appeared to be a more potent treatment against dengue fever; however, further studies are required to demonstrate this clearly.
\end{abstract}

Keywords: Dengue, Hematocrit, Homeopathy, Platelet, Blood count.

Tropical Journal of Pharmaceutical Research is indexed by Science Citation Index (SciSearch), Scopus, International Pharmaceutical Abstract, Chemical Abstracts, Embase, Index Copernicus, EBSCO, African Index Medicus, JournalSeek, Journal Citation Reports/Science Edition, Directory of Open Access Journals (DOAJ), African Journal Online, Bioline International, Open-J-Gate and Pharmacy Abstracts

\section{INTRODUCTION}

Dengue is endemic in more than 110 countries. It infects 50 to 100 million people worldwide a year, leading to half a million hospitalizations, and approximately $12,500-25,000$ deaths. The incidence of dengue increased 30 -fold between 1960 and 2010. This increase is believed to be due to a combination of urbanization, population growth, increased international travel, and global warming [1]. It is an acute and severe febrile disease. Fever is attended by prostration, chills, intense headache, retro-ocular pain, muscular and joints pain. Nausea, vomiting, sore throat and adenopathy may be found [2]. At the end of the febrile phase of illness or after the temperature falls to or below normal, petechiae may appear; these may be scattered or confluent. GI hemorrhage is found at fever are common and range from mild to severe epistaxis, menorrhagia, and gastrointestinal (Gl) bleeds. Thrombocytopenia and haemoconcentration are constant findings in Dengue hemorrhagic fever 
(DHF) and Dengue shock syndrome (DSS). A platelet count of $\leq 100 \times 10^{3} / \mu \mathrm{L}$ is usually found between the days 3 and 8 of illness [3]. There are no specific medications which can successfully deal with the dengue fever in allopathic medicine. Because dengue epidemics have increased in extension and virulence, possibly indicating viral mutation of 4 existing varieties of it makes difficult to produce an effective vaccine [2]. Acetaminophen with fluid replacement may be used to treat patients with symptomatic fever [4-7].

Homeopathy as cited by WHO has been used successfully for the prevention and treatment of a number of infectious diseases, including influenza and diarrhea [8-11] and also have found to be a major contributor to attenuate the symptoms of dengue fever. To the best of our knowledge, there have been no previous studies that evaluated the efficacy of homeopathy medications in dengue fever in terms of their effect on clinical hematological parameters. Hence, the main objective of the study was to analyze and determine, with the aid of hematological data, whether homeopathic remedies can aid in minimizing the progression and severity of the disease or shortening the clinical course of the disease.

\section{EXPERIMENTAL}

\section{Study medication}

The homeopathic treatment used in the study was the combination of ten herbal and mineral medicines including Bryonia alba, Rhus toxicodendron, Gelsemium sempervirens, Aconitum napellus, Eupatorium perfoliatum, China boliviana, Hamamelis, Citrullus colocynthis, Crotilus Horridus and phosphorus that were in pure tincture form The homeopathic combination used was of $30 \mathrm{C}$ potency each, which means that the original tinctures were diluted 1:100 in a water/alcohol solution thirty times. This process was done by taking one $\mathrm{ml}$ of original tincture and adding to $99 \mathrm{ml}$ of water/alcohol mixture. One $\mathrm{ml}$ of the resulting solution was added to $99 \mathrm{ml}$ of water/alcohol solution to make second dilution. The dilution process was carried out a total of 30 times to give $30 \mathrm{C}$ potency solution. The medicines were then combined by taking $5 \mathrm{ml}$ of each $30 \mathrm{C}$ potency solution in an empty dispensing bottle and used to impregnate lactose tablets in a rotating bottle. The tablets were given three times a day by oral route. WHO recommended standard maintenance therapy for symptomatic treatment was given following $\mathrm{WHO}$ guidelines; it took into consideration the severity of symptoms, e.g., for fever persistently > $39{ }^{\circ} \mathrm{C}$, acetaminophen was given. For the nausea and vomiting dimenhydrinate (gravinate) was given. Gastro-protective agents such as ranitidine, omeprazole or lansoperazole was given. Fluid replacement therapy was initiated with intravenous $5 \%$ dextrose/normal saline solution (D/NSS) with the quantity and infusion rate to be adjusted according to vital signs and physical state of patient.

\section{Study design and treatment of patients}

The study was carried out in accordance with the WHO guidelines. Prior to starting, ethical approval was obtained from the ethical committee of Muahammdi Hospital, Lahore, Pakistan (ref no. 3119 dated 09 September2011). All the patients were informed verbally and in writing about the study. Signed informed consent was obtained from all the patients. A total of 50 patients $(40$ males and 10 females) over the age of 18 with the symptoms of dengue (persistent fever for $>3$ days of $>37{ }^{\circ} \mathrm{C}$ with any of the two following symptoms: headache, retro-orbital pain, myalgia, arthralgia, or skin rash) with low platelet count $(<100 \mathrm{x}$ $10^{3} / \mu \mathrm{L}$ ) were included. Patients that fell within the dengue shock syndrome category were excluded. Patients with any concomitant diseases, either short or long term, were also excluded.

The patients were divided into two groups. Patient's demographic information (age, sex and location) was collected at the initial visit and their past medical history, date of onset and severity of current symptoms and use of medications for current illness were recorded using patient data collection form. The subjects then were given a complete physical examination and blood samples were obtained. Group 1 was given homeopathic combination remedy while Group 2 was treated with standard maintenance therapy as per WHO guidelines [7]. A complete blood count, including platelet count, WBC and hematocrit profile, were obtained after every $24 \mathrm{~h}$ for 6 days using Sysmex KX-21 automated hematology analyzer.

\section{Statistical analysis}

The mean values of each of the criteria of both groups were compared. The data were analyzed by SPSS 13.0 using Student t-test. Differences were considered significant at $p<0.05$. 


\section{RESULTS}

As shown in Table 1, after homeopathic combination treatment on the first day, mean platelet count, WBC and hematocrit values were $95.6 \times 10^{3} \pm 43.6$ and $7.95 \times 10^{3} / \mu \mathrm{L} \pm 4.96$, and $48.02 \% \pm 6.70$ respectively, while for standard maintenance therapy, the values were $73.44 \mathrm{x}$ $10^{3} \pm 39.2$ and $5.35 \times 10^{3} / \mu \mathrm{L} \pm 1.85$, and 42.32 $\% \pm 2.48$, respectively. The result of first day showed that there was not a significant difference in mean platelets count while a very significant difference were found in WBC and hematocrit values $(p=0.055,0.020$ and 0.000 , respectively). At the end of the $6^{\text {th }}$ day of homeopathic combination treatment and standard maintenance therapy, the mean platelet count, WBC and hematocrit were $311 \times 10^{3}, 9.03$ $x 10^{3} / \mu \mathrm{L}$ and $42.30 \%$, respectively while for standard maintenance therapy, the values were $239 \times 10^{3}$, and $7.94 \times 10^{3} / \mu \mathrm{L}$, and $39.68 \%$, respectively, which indicate significant difference between the two therapies $(p=0.012,0.003$ and 0.021 respectively) Platelet and WBC counts increased on daily basis while hematocrit count decreased. Significant differences between the two groups for all the parameters were observed on the $6^{\text {th }}$ day of treatment (Fig 1).

\section{DISCUSSION}

A homeopathic literature survey found many references for homeopathic medicines, including Aconitum napellus (Monkshood), Belladonna (Deadly Nightshade), Bryonia alba (Wild Hops), Eupatorium perfoliatum (Thoroughwort), Gelsemium (Yellow Jasmine), Rhus toxicodendron (Poison ivy) for the treatment of symptoms of dengue fever [12]. In this study homeopathic formulation was composed of Bryonia alba, Rhus toxicodendron, Gelsemium sempervirens, Aconitum napellus, Eupatorium perfoliatum, Citrullus colocynthis, China boliviana, Hamamelis, Crotilus horridus and phosphorus. It was desinged to attenuate the intensity of symptoms of dengue and prevent hemorrhagic complications by increasing blood count. A drop in the platelet count to below

Table 1: Blood profile (mean \pm standard deviation) after administration of homeopathic formulation and standard maintenance therapy

\begin{tabular}{|c|c|c|c|c|c|c|c|}
\hline Group & Parameter & Day 1 & Day 2 & Day 3 & Day 4 & Day 5 & Day 6 \\
\hline \multirow{3}{*}{1} & $\begin{array}{c}\mathrm{PLT} \pm \mathrm{SD} \\
\left(10^{3} / \mu \mathrm{L}\right)\end{array}$ & $95.6 \pm 43.6$ & $77.7 \pm 18.1$ & $116.9 \pm 41.0$ & $166.0 \pm 31.6$ & $237.0 \pm 90.9$ & $311 \pm 128$ \\
\hline & $\begin{array}{l}\text { WBC } \pm \text { SD } \\
\left(10^{3} / \mu \mathrm{L}\right)\end{array}$ & $7.95 \pm 4.96$ & $7.97 \pm 3.83$ & $8.04 \pm 2.99$ & $8.26 \pm 2.11$ & $8.76 \pm 1.92$ & $9.03 \pm 2.07$ \\
\hline & $\begin{array}{c}\mathrm{HCT} \pm \mathrm{SD} \\
(\%)\end{array}$ & $48.03 \pm 6.70$ & $49.07 \pm 5.22$ & $46.94 \pm 4.16$ & $45.85 \pm 2.65$ & $44.14 \pm 2.41$ & $42.32 \pm 3.42$ \\
\hline \multirow{3}{*}{2} & $\begin{array}{l}\text { PLT } \pm S D \\
\left(10^{3} / \mu \mathrm{L}\right)\end{array}$ & $73.4 \pm 39.2$ & $63.7 \pm 48.8$ & $75.4 \pm 47.9$ & $95.7 \pm 58.7$ & $163.4 \pm 58.2$ & $239 \pm 40.7$ \\
\hline & $\begin{array}{c}\text { WBC } \pm S D \\
\left(10^{3} / \mu \mathrm{L}\right)\end{array}$ & $5.35 \pm 1.85$ & $5.38 \pm 1.31$ & $6.20 \pm 4.27$ & $7.45 \pm 4.00$ & $7.54 \pm 3.02$ & $7.94 \pm 1.91$ \\
\hline & HCT \pm S.D (\%) & $42.30 \pm 2.48$ & $40.51 \pm 3.54$ & $40.55 \pm 6.48$ & $36.64 \pm 4.35$ & $36.56 \pm 4.04$ & $39.68 \pm 4.35$ \\
\hline
\end{tabular}

* Significantly different $(p<0.05)$; SD = standard deviation

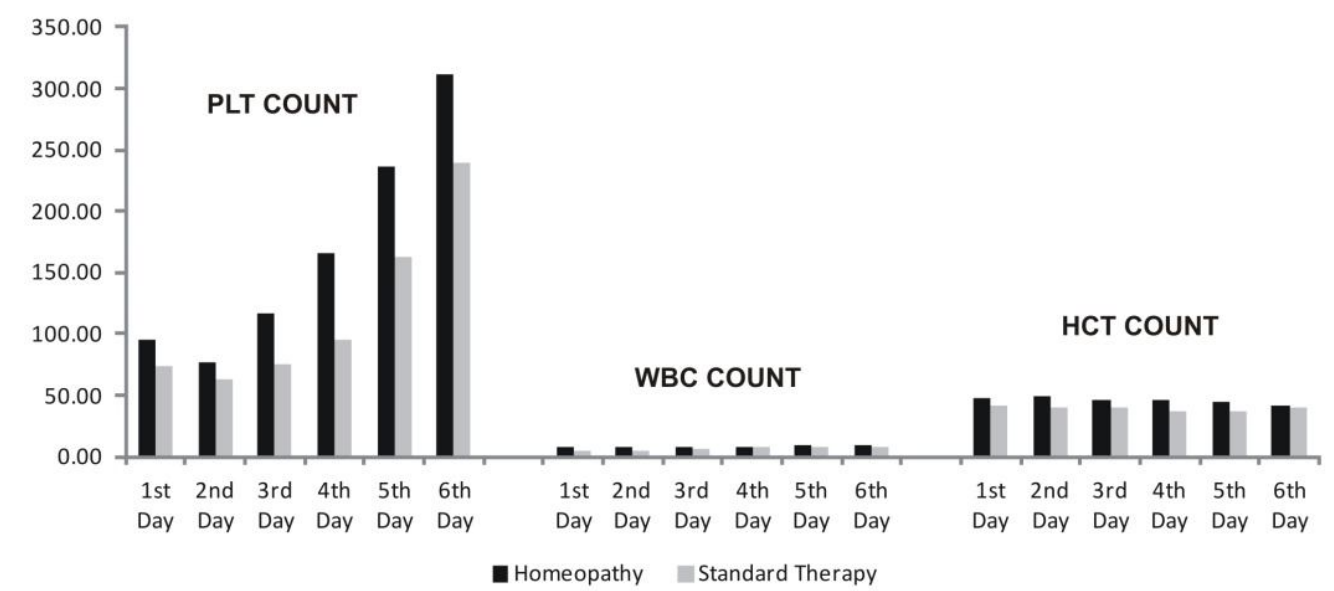

Figure 1: Complete blood count ( $\mathrm{CBC})$ profile of dengue patients after homeopathy and standard therapy 
100,000 per $\mathrm{mm}^{3}$ was found between the $3^{\text {rd }}$ and $6^{\text {th }}$ day of illness of dengue, often before or simultaneous with changes in haematocrit. A rise in haematocrit level indicates plasma leakage was present and a drop in total WBC may be due to a reduction in the number of neutrophils observed near the end of the febrile phase of illness. The use of homeopathic combination showed increase in platelet and WBC counts and decreased hematocrit level.

As reported by Central Council of Research in Homoeopathy, India that out of 23,520 people from dengue hemorrhagic fever, only 5 people $(0.125 \%)$ developed mild symptoms, with the rest showing no signs or symptoms of the disease after a 10-day homeopathic treatment [13]. Migowski also reported that the use of eupatorium perfoliatum showed better clinical outcome against classic Dengue, while phosphorus having affinity for the liver produce effects on the functional integrity of this organ and on the production of coagulation factors, while Crotalus horridus showed good activity against dengue hemorrhagic fever [14]. Robin reported that the Aconitum napellus has good effect in high grade fever while Bryonia alba and Eupatorium perfoliatum exhibited therapeutic activity against bone fever and pain behind the eye balls. Citrullus colocynthis, China boliviana, and Hamamelis indicated in hemmorhagic conditions while Rhus toxicodendron and Gelsemium sempervirens are mainly prescribed in urtacaria and skin infections, phosphorous in anemia. Therefore, the combination of these drugs has a substantial capacity to control dengue symptoms and improve hematological parameters [15].

\section{Limitation of the study}

This study was conducted on a small sample of the population which could have some influence on the results obtained.

\section{CONCLUSION}

The homeopathic formulation tested showed a greater therapeutic effect on Dengue than WHO- recommended standard maintenance therapy. Thus the homeopathic remedy could be an effective tool to fight this life-threatening disease; however, further work is required to ascertain the true value of the formulation in Dengue therapy.

\section{REFERENCES}

1. Wilson $N$, Slaney D, Baker MG, Hales $S$, Britton E. Climate change and infectious diseases in New Zealand: a brief review and tentative research agenda. Rev Environ Health 2011; 26(2): 93-99.

2. Marino R. Homeopatia em saúde coletiva: contribuição ao estudo de epidemias [Dissertation (MSc)]. São José do Rio Preto: Faculdade de Medicina de São José do Rio Preto, 2006.

3. Putnam JL, Scott TW. Age-Dependent Effects of Oral Infection with Dengue Virus on Aedes aegypti (Diptera: Culicidae) Feeding Behavior, Survival, Oviposition Success and Fecundity. Trop. AJ. Med. Hyg 1995; 55: 225-227.

4. Murthy JM, Rani PU. Biological activity of certain botanical extracts as larvicides against the yellow mosquito, Aedes aegypti. J Biopest 2009; 2: 72-76.

5. Akram W, Khan HAA, Hafeez F, Bilal H, Kim YK, Lee JJ. Potential of citrus seed extracts against dengue fever mosquito, Aedes albopic Tus (Skuse) (Culicidaea). Pak J Bot 2010; 42: 3343-3348.

6. Maheswaran $R$, Satish $S$, Ignacimathu S. Larvicidal activity of Leucas asper (Willd) against the larvae of Culex quinquefasciatus Say. and Aedes aegypti I. Inter J Intergrative Biol 2008; 2: 214-217.

7. Morens F, Brody JE. Mosquito thrives; so does dengue fever. Geneva: WHO, 2008.

8. Ferley JP, Smirou D, D'Adhemar D, Balducci F. A controlled evaluation of a homeopathic preparation in the treatment of influenza-like syndromes. $\mathrm{Br} \mathrm{J}$ Clin Pharmacol 1989; 27: 329-335.

9. Jacobs J, Jimenez LM, Gloyd S, Carares FE, PaniaguaGaitan M, Crothers D. Homeopathic treatment of acute childhood diarrhea. Bri Homeopath J 1993; 82: 83-86.

10. Jacobs J, Jimenez LM, Gloyd S, Gale J, Crothers D. Treatment of acute childhood diarrhea with homeopathic medicine: a randomized clinical trial in Nicaragua. Pediatrics 1994; 93: 719-725.

11. Jacobs J, Jimenez LM, Malthouse $S$, et al. Homeopathic treatment of acute childhood diarrhea: results from a clinical trial in Nepal. J Altern Complement Med 2000; 6: 131-139.

12. Schroyens F (ed.). Synthesis: Repertorium Homeopaticum Syntheticum, 6th edn. London: Homeopathic Book Publishers, 1996.

13. Central Council of Research in Homoeopathy. CCRH News 1996-1997.

14. Migowski E. Uso de antitérmicos em doenças infecciosas virais. São Paulo. Abbott do Brasil, 2002.

15. Robin MND. Lotus Materia Medica, $2^{\text {nd }}$ edn, New Dehli: $B$ Jian Publishers, 2000. 